\title{
Hypertrophy of the transverse ligament caused by os odontoideum: a case report
}

\author{
Seda Avnioğlu' ${ }^{1}$, Vaner Köksal ${ }^{2}$, Tolga Ertekin ${ }^{3}$ \\ ${ }^{1}$ Department of Anatomy, Faculty of Medicine, Alanya Alaaddin Keykubat University, Antalya, Turkey \\ ${ }^{2}$ Department of Neurosurgery, Faculty of Medicine, Recep Tayyip Erdoğan University, Rize, Turkey \\ ${ }^{3}$ Department of Anatomy, Faculty of Medicine, Afyon Kocatepe University, Afyonkarahisar, Turkey
}

\begin{abstract}
Os odontoideum is a small oval or round shaped bone fragment observed as the most common congenital anomaly of the odontoid process. Since it causes a slowly increasing mobility or instability in the atlanto-axial joint, sudden death, tetraplegia, chronic neck pain, headache, torticollis and myelopathy may develop. The spinal canal widens initially at the craniocervical junction and symptoms can occur at a very late stage. In this case, clinical complaints emerged after the age of 35 . There was no other neurological finding and no history of recent trauma in this case presenting with severe neck pain. This case report shows how ligaments, the supporting connective tissue elements, can be thickened to maintain stability when the stability of the cervical spine is impaired. Since it may cause sudden death even when asymptomatic, it is important to recognize this pathology and to distinguish os odontoideum from odontoid fractures in trauma patients.
\end{abstract}

Keywords: anatomy; atlantoaxial dislocation; hypertrophy of the transverse ligament; instability; os odontoideum

Anatomy 2017;11(3):149-152 (02017 Turkish Society of Anatomy and Clinical Anatomy (TSACA)

\section{Introduction}

Os odontoideum $(\mathrm{OO})$ is a craniovertebral junction (CVJ) abnormality in which an ossicle (small bone) is cranial to a hypoplastic dens by a variable gap. This abnormality can result in instability, which may be reducible or irreducible. What leads to irreducibility in $\mathrm{OO}$ is unclear. ${ }^{[1]}$

$\mathrm{OO}$ was first described as a postmortem finding by Giacomini in $1880 .^{[2-4]}$ Odontoid process of the axis has many variations that may either be congenital or acquired and lead to mild or severe instability of the atlanto-axial joint leading to potential defects on the medulla or upper cervical cord with neurological symptoms. ${ }^{[5]}$ The identified congenital anomalies of the odontoid process are aplasia, hypoplasia, duplication, condylus tertius, ossiculum terminale (os avis), and $\mathrm{OO}{ }^{[6,7]} \mathrm{OO}$ is the most common anomaly of the odontoid process. $^{[6,8,9]}$

The etiology of OO remains controversial, but there is emerging consensus on both the traumatic etiology and a congenital source. Some studies reported that post-traumatic displacement or an unrecognized fracture of the odontoid process may result in $\mathrm{OO}$ prior to ossification. ${ }^{[10]}$ There is a progressive spondylolisthesis between C1 and C2 such as traumatic spondylolisthesis caused by hangman type fractures of the second cervical vertebra. ${ }^{[1]}$ Therefore, trauma at etiology is often considered. Some studies suggested that $\mathrm{OO}$ may be a result of congenital segmentation anomaly due to failure of fusion of the ossiculum terminale. ${ }^{[10,12]}$ Hypertrophy of the transverse ligament has been shown to maintain of the biomechanical stability, but the spinal channel is narrowed.

In this case report, we aimed to demonstrate a case report with hypertrophy of the transverse ligament caused by $\mathrm{OO}$ and emphasize that changes in the supporting connective tissue anatomy prevents instability in the cervical spine.

\section{Case Report}

A 35-year-old female patient was admitted to the Department of Neurosurgery, Faculty of Medicine, Recep 
Tayyip Erdoğan University, Rize, Turkey with the complaint of increased persistent pain in the back of the neck for two years. The patient did not have any complaints in using his hands and in his walk. Neurological evaluation revealed no pathological reflexes or motor defects. In addition, there were no any trauma, accident, fall or bump in the history of the patient.

Coronal, sagittal and axial computed tomography (CT) images demonstrated that the apical portion of the odontoid bone was already separated (Figures 1a-c). Initial magnetic resonance imaging (MRI) revealed anterior spinal cord compression at the CVJ due to hypertrophy of the transverse ligament, which is located posterior to the odontoid bone and is responsible for its movement (Figures 1d and e). We identified the pathology as OO. Stabilization surgery was performed to connect $\mathrm{C} 1$ and $\mathrm{C} 2$ bones through the posterior neck in order to prevent serious neurological damage that could develop in the patient. The patient was followed up for four years after the surgery (Figures 2a-c). Neck pain completely improved and neurological problem was not observed until this date.

\section{Discussion}

OO can be divided into two main types: dystopic and orthotopic. ${ }^{[2,13]}$ Anomalies of the odontoid process are not observed frequently and are usually noticed after trauma and sometimes in randomized examinations. They may be associated with Down syndrome, Klippel-Feil spectrum, Morquio syndrome, and spondyloepiphyseal dysplasia. The caudal portion of the odontoid process normally completes its development, which is comprised of two lateral ossification centers. ${ }^{[14]}$ However, it may not combine with the body of the second cervical vertebrae at the level of the neurocentral synchondrosis. Since there is no bone defect at the level of the growth plate, it is also thought that $\mathrm{OO}$ is actually formed by non-union of a long-term and unrecognizable fracture. ${ }^{[6,8,15]}$ It has been found in some cases that the atlantoaxial dislocation occurred after trauma. ${ }^{[6,8,16,17]}$ Some studies reported that the odontoid process normally developed, but could not combine with the body of $\mathrm{C} 2$ due to abnormal mobility. ${ }^{[9,18]}$ It must be completely combined with the body of
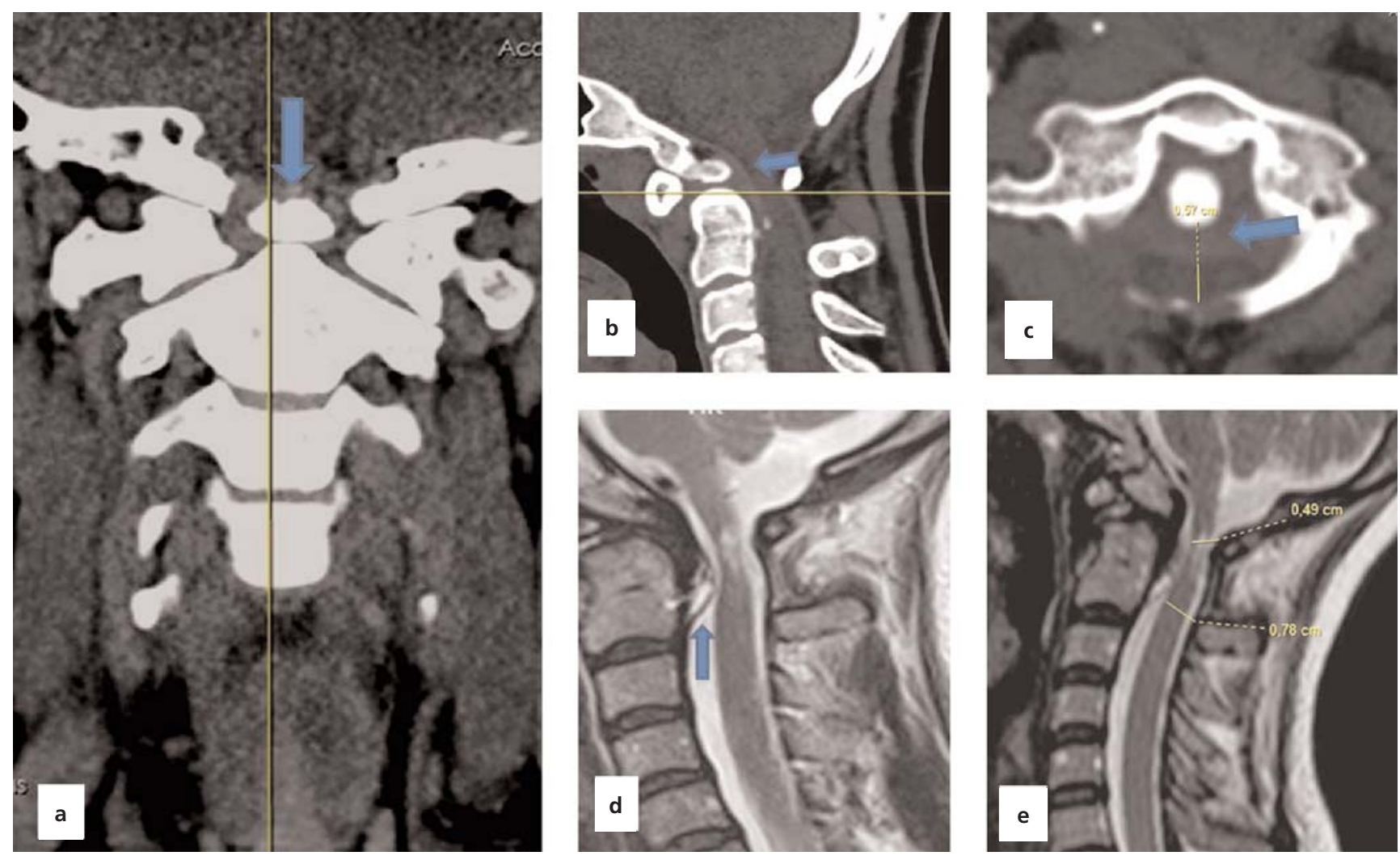

Figure 1. (a) Pre-operative coronal, (b) sagittal and (c) axial computed tomography views. Free apical bone on the odontoid process in preoperative coronal tomography is marked with blue arrow. Especially, transverse ligament hypertrophy viewed on axial and sagittal computed tomography plan with blue arrow. (d and e) Narrow spinal canal on sagittal T2 MRI viewed caused by hipertrophy of the transverse ligament due to os odontoideum. [Color figure can be viewed in the online issue, which is available at www.anatomy.org.tr] 
C2 between the ages of 5 and $7 \cdot^{[8,9,18-21]}$ Associated with this, symptoms usually occur due to atlantoaxial instability and cord compression. If accompanied vertebral artery compression is present, the symptoms become more pronounced. ${ }^{[8]}$

Many subjects with $\mathrm{OO}$ remain asymptomatic throughout their life and might be only discovered incidentally. ${ }^{[7,10-12,22]}$ Excessive mobility of the atlantoaxial joint causes repetitive minor trauma in the spinal cord, blood vessels and meninges and intermittent obstruction in the vertebral and anterior spinal arteries with flexion, extension or rotation of the neck. Sudden death and tetraplegia may occur. Persistent or chronic neck pain, headache, torticollis, and myelopathy may also occur due to instability between $\mathrm{C} 1$ and $\mathrm{C} 2$ associated with $\mathrm{OO}$ and even the development of dislocation. ${ }^{[1,8,12]}$ Brown-Sequard syndrome caused by partial compression of cervical spinal cord may also be observed. ${ }^{[23]}$

Fielding et al. ${ }^{[15]}$ described 35 patients with $\mathrm{OO}$ and detected radiographic instability in 27 of 35 patients. They performed successful posterior C1-C2 internal fixation and fusion to 26 of 27 patients with instability (Gallie type). Dai et al. ${ }^{[2]}$ described 44 patients (33 men and 11 women) with $\mathrm{OO}$ between ages 7 and 56 years. 26 patients had no any history of trauma. Clinical examination of the patients revealed both myelopathy and radiculopathy in 22 patients. Spierings and Braakman reported a series of 37 patients with OO. Flexion-exten- sion cervical spine radiograph or computed tomography was performed. They concluded that the degree of $\mathrm{C1}$ C2 instability was incompatible with neurological status and myelopathy grade in 21 of 37 patients. ${ }^{[24]}$

Since the spinal canal is wide at the CVJ in patients with $\mathrm{OO}$, symptoms may appear at a very late stage. ${ }^{[2]}$ In this case, the spinal canal width was significantly reduced because the transverse ligament of the atlas, which holds the odontoid process, was hypertrophied. However, the patient still tolerated it neurologically. It is known that connective tissues (ligaments) support correct alignment of the bones and joints of the body. It has been reported that if there is a deterioration of stability or a defect in the bone roof, connective tissue can undergo hypertrophy on the ligamentum flavum and the posterior longitudinal ligament. $^{[25-27]}$

Consequently, this pathology which may cause sudden death should be distinguished from odontoid fractures in trauma patients. Therefore, the anatomy of the cervical spine bones and ligaments holding them together must be well known. In cases with OO, MRI should not be sufficient and also $3 \mathrm{D}$ computed tomography (CT) imaging should be performed to check whether it is fractured. We think that surgery should be decided after distinguishing features are determined by dynamic direct radiography or dynamic MRI for acute or initial instability.
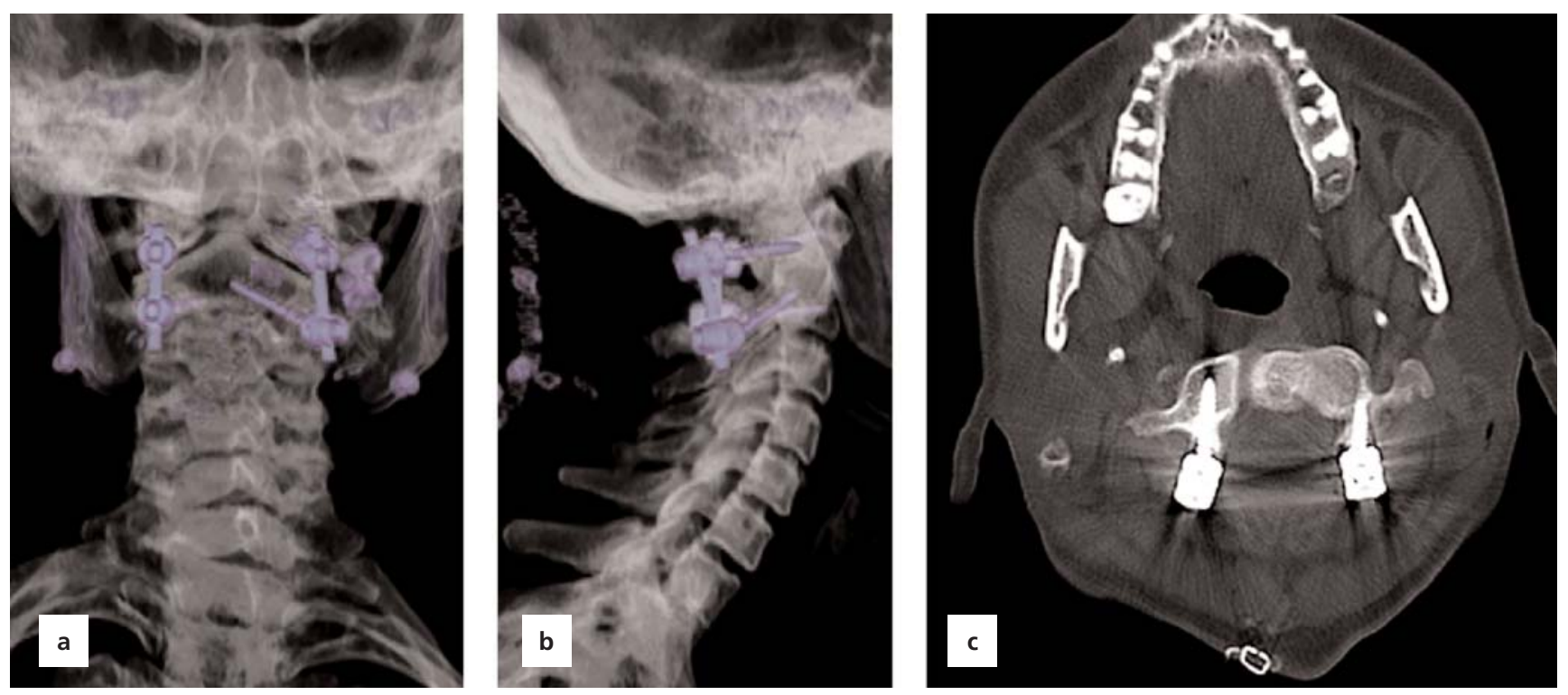

Figure 2. (a, b) OO stabilized with pedicle screws on post-operative view with X-ray. (c) Post-operative axial computed tomogragy at the level of the $\mathrm{C} 1$ total laminectomy. Spinal cord decompressed with C1 total laminectomy. [Color figure can be viewed in the online issue, which is available at www.anatomy.org.tr] 


\section{References}

1. Dlouhy BJ, Policeni BA, Menezes AH. Reduction of atlantoaxial dislocation prevented by pathological position of the transverse ligament in fixed, irreducible os odontoideum: operative illustrations and radiographic correlates in 41 patients. J Neurosurg Spine 2017; 27:20-8.

2. Moosa S, Andronikou S. Spastic quadraparesis following a relatively minor injury - the 'os odontoideum'. South African Journal of Radiology 2006;10:34-6.

3. Dai L, Yuan W, Ni B, Jia L. Os odontoideum: etiology, diagnosis, and management. Surg Neurol 2000;53:106-8.

4. Galli J, Tartaglione T, Calo L, Ottaviani F. Os odontoideum in a patient with cervical vertigo: a case report. Am J Otolaryngol 2001; 22:371-3.

5. Akobo S, Rizk E, Loukas M, Chapman JR, Oskouian RJ, Tubbs RS. The odontoid process: a comprehensive review of its anatomy, embryology, and variations. Childs Nerv Syst 2015;31:2025-34.

6. Klimo P Jr, Coon V, Brockmeyer D. Incidental os odontoideum: current management strategies. Neurosurg Focus 2011;31:E10.

7. Kotil K. Os odontoideum. Turk Noroşirurji Dergisi 2015;2:170-6.

8. Yıldız A, Apaydın FD, Özer C, Eğilmez H, Duce MN, Yalçınoğlu O. Kranyovertebral bölge ve servikal vertebra anomalileri. Diagnostic and Interventional Radiology 2001;7:38-42.

9. Kaya RA, Turkmenoğlu O, Çavuşoglu H, Kahyaoğlu O, Aydın Y. Os odontoideum: a case report. Turk Neurosurg 2005;15:157-61.

10. Tommy KY, Ratnayake K. Os odontoideum discovered after minor cervical trauma. Pediatr Emerg Care 2017;2:104-6.

11. Köksal V, Kayacı S, Coşkun S. Hangman fracture treated using cervical collar. Journal of Emergency Medicine Case Reports 2014;5: 127-130.

12. Candan B, Tomruk O, Yildiz O, Albay S. Dens fracture or odontoid bone. International Journal of Anatomical Variations 2014;7:14-6.

13. Rozzelle CJ, Aarabi B, Dhall SS, Gelb DE, Hurlbert RJ, Ryken TC, Theodore N, Walters BC, Hadley MN. Os odontoideum. Neurosurgery 2013;72:159-69.

14. Weng C, Tian W, Li ZY, Liu B, Li Q, Wang YQ, Sun YZ. Surgical management of symptomatic os odontoideum with posterior screw fixation performed using the magerl and harms techniques with intraoperative 3-dimensional fluoroscopy-based navigation. Spine (Phila Pa 1976) 2012;37:1839-46.

15. Fielding JW, Hensinger RN, Hawkins RJ. Os odontoideum. J Bone Joint Surg Am 1980;62:376-83.

16. Hukuda S, Ota H, Okabe N, Tazima K. Traumatic atlantoaxial dislocation causing os odontoideum in infants. Spine (Phila Pa 1976) 1980;5:207-10.

17. Fielding JW, Griffin PP. Os odontoideum: an acquired lesion. J Bone Joint Surg 1974;56:187-90.

18. Stevens JM, Chong WK, Barber C, Kendall BE, Crockard HA. A new appraisal of abnormalities of the odontoid process associated with atlanto-axial subluxation and neurological disability. Brain 1994;117: 133-48.

19. Yucesoy K, Yuksel M, Kalemci O, Yuksel KZ. Os odontoideumlu bir olgunun radyolojik görüntüleme bulguları ve ayırıcı tanısı: olgu sunumu. Sinir Sistemi Cerrahisi Dergisi 2010;3:84-8.

20. Kirlew KA, Hathout GM, Reiter SD, Gold RH. Os odontoideum in identical twins: perspectives on etiology. Skeletal Radiol 1993;22: $525-7$.

21. Morgan MK, Onofrio BM, Bender CE. Familial os odontoideum. Case report. J Neurosurg 1989;70:636-9.

22. Rahimizadeh A, Soufiani HF, Hassani V, Rahimizadeh A. Atlantoaxial subluxation due to an os odontoideum in an achondroplastic adult: report of a case and review of the literature. Case Rep Orthop 2015; 2015:142586.

23. Koksal V, Yavasi O. Controversies in the differential diagnosis of Brown-Sequard syndrome due to cervical spinal disease from stroke: a case series. Turk J Emerg Med 2017;17:115-20.

24. Spierings EL, Braakman R. The management of os odontoideum: analysis of 37 cases. J Bone Joint Surg Br 1982;64:422-8.

25. Liu H, Wang T, Wang H, Ding WY. Posterior decompression and internal fixation in treatment of hypertrophy of posterior longitudinal ligament at C1-2 level accompanied with lower cervical spinal stenosis: a case report. Medicine (Baltimore) 2016;95:e5600.

26. Karavelioglu E, Kacar E, Gonul Y, Eroglu M, Boyaci MG, Eroglu S, Unlu E, Ulasli AM. Ligamentum flavum thickening at lumbar spine is associated with facet joint degeneration: an MRI study. J Back Musculoskelet Rehabil 2016;29:771-7.

27. Fukuyama S, Nakamura T, Ikeda T, Takagi K. The effect of mechanical stress on hypertrophy of the lumbar ligamentum flavum. J Spinal Disord 1995;8:126-30.

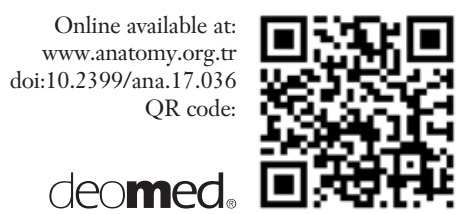

Correspondence to: Seda Avnioğlu, PhD

Department of Anatomy, Faculty of Medicine, Alanya Alaaddin

Keykubat University, Alanya, Antalya, Turkey

Phone: +90 2425106060

e-mail: seda.avnioglu@alanya.edu.tr

Conflict of interest statement: No conflicts declared.

This is an open access article distributed under the terms of the Creative Commons Attribution-NonCommercial-NoDerivs 3.0 Unported (CC BY-NCND3.0) Licence (http://creativecommons.org/licenses/by-nc-nd/3.0/) which permits unrestricted noncommercial use, distribution, and reproduction in any medium, provided the original work is properly cited. Please cite this article as: Avnioğlu S, Köksal V, Ertekin T. Hypertrophy of the transverse ligament caused by os odontoideum: a case report. Anatomy 2017;11(3):149-152. 